\title{
PERANAN ANGGOTA KELOMPOK WANITA TANI (KWT) DALAM MEWUJUDKAN DESA AGROWISATA SUNGAI LANGKA KECAMATAN GEDONG TATAAN KABUPATEN PESAWARAN
}

\author{
(The Role of Woman Farmer Group Members in Actualizing the Sungai Langka Agrotourism Village of \\ Gedong Tataan Sub-district of Pesawaran Regency)
}

Yudia Anggun Kirana, Irwan Effendi, Serly Silviyanti

\begin{abstract}
Jurusan Agribisnis, Fakultas Pertanian, Universitas Lampung, Jl. Prof. Dr. Soemantri Brodjonegoro No. 1 Bandar Lampung, Telp. 081295645414,e-mail: yudiaanggun@ gmail.com
\end{abstract}

\begin{abstract}
This research aims to determine the role of Woman Farmer Group (KWT) members and factors related to the role of KWT in actualizing Sungai Langka as an Agrotourism Village. The research location was chosen purposively in Sungai Langka Village of Gedong Tataan Sub-district of Pesawaran Regency. Respondents were 61 respondents using Proportional Random Sampling. This research was conducted from January to February 2018. Data analysis method used descriptive method with quantitative approach. To answer the first purpose used descriptive analysis, and the second goal by using a quantitative approach of Rank Spearman analysis method. The results indicated that the role level of KWT members in mini jackfruit planting and handicraft production is included in a low classification, the roles of KWT members in the manufacture of vegetable quoting galleries, fruit pickling and in Small and Medium Enterprises processing of agricultural products are included in medium classification, KWT in actualizing as Sungai Langka Agrotourism Village is generally included in the middle classification. Factors associated with the role of KWT members in actualizing the Agrotourism Village Sungai Langka are the motivation, cosmopolite character, and the level of knowledge. Whereas, the age and level of education were not significantly related to the role of KWT members in actualizing Sungai Langka Village as the Agrotourism Village.
\end{abstract}

Key words: agrotourism village, KWT members, role

\section{PENDAHULUAN}

Kesenjangan antara kawasan perkotaan dan pedesaan telah mendorong upaya-upaya pembangunan di kawasan pedesaan. Pembangunan desa bertujuan untuk memperbaiki kondisi sosial, ekonomi, dan budaya masyarakat (Korten dan Syahrir 1988).

Desa Sungai Langka merupakan salah satu desa di Kabupaten Pesawaran yang selalu melakukan kegiatan pembangunan desa. Desa Sungai Langka sebenarnya mempunyai banyak potensi yang menjanjikan untuk menjadi desa mandiri. Dalam bidang peternakan, Desa Sungai Langka menjadi daerah pengembang peternakan kambing Etawa terbesar di Lampung, sedangkan dalam bidang perikanan merupakan daerah pembudidaya ikan air tawar seperti ikan gurame dan ikan nila. Sebagian besar Desa Sungai Langka terdiri dari wilayah kebun rakyat dengan luas $576 \mathrm{Ha}$ yang ditanami dengan berbagai macam tanaman antara lain tanaman hortikultura, perkebunan, dan pangan. Kemudian terdapat pula potensi dari sektor home industry yang dimiliki oleh warga Desa Sungai
Langka, usaha home industry yang paling banyak dilakukan oleh warga yaitu usaha yang mengolah/memanfaatkan hasil pertanian seperti keripik pisang, keripik nangka, bubuk susu kambing etawa, dll (Laboratorium Desa Fakultas Pertanian Universitas Lampung 2017)

Salah satu cara untuk mewujudkan desa mandiri yaitu dengan cara mengelola potensi-potensi yang dimiliki oleh desa. Didukung dengan adanya visi misi Desa Sungai Langka yaitu menjadikan Desa Sungai Langka sebagai desa mandiri dan kreatif dengan cara mewujudkan Desa Agrowisata Sungai Langka yang SIMPATIK (Sehat, Indah, Makmur, Patuh, Aman, Taqwa, Iman dan Kreatif). Desa agrowisata merupakan rangkaian kegiatan wisata yang memanfaatkan potensi pertanian sebagai obyek wisata, baik potensial berupa pemandangan alam kawasan pertanian maupun kekhasan dan keanekaragaman aktivitas produksi dan teknologi pertanian serta budaya masyarakat (Maruti 2009).

Upaya mewujudkan desa agrowisata ini sangat diperlukan untuk memberdayakan sumberdaya manusia sekitar. Menurut Hubeis dalam Badan 
Litbang Pertanian (2015), pelaksanaan pembangunan akan berhasil, jika semua sumberdaya manusia diberdayakan, tidak hanya sumberdaya laki-laki tetapi juga wanita. Pemberdayaan wanita di pedesaan bertujuan untuk menghapuskan kesenjangan sosial terhadap kaum wanita. Upaya pemberdayaan ini harus pula dilatarbelakangi dengan sumberdaya manusia yang dimiliki desa. Masyarakat Desa Sungai Langka mayoritas bermatapencaharian sebagai petani, perlu adanya pemberdayaan wanita yang berlatar belakang sebagai petani.

Kelompok Wanita Tani (KWT) merupakan salah satu wadah bagi para petani wanita, KWT berbeda dengan kelompok tani lainnya, dalam pembinaannya KWT diarahkan untuk mempunyai suatu usaha produktif dalam skala rumah tangga yang memanfaatkan atau mengolah hasil-hasil pertanian maupun perikanan. Adanya keterlibatan atau peran KWT ini diharapkan tidak hanya meningkatkan kesejahteraan keluarganya saja, melainkan dapat berperan dalam mewujudkan Desa Agrowisata Sungai Langka.

Berdasarkan uraian di atas, tujuan dari penelitian ini adalah untuk mengetahui peranan anggota KWT dalam mewujudkan Desa Agrowisata Sungai Langka dan untuk mengetahui faktor-faktor apa saja yang berhubungan dengan peranan anggota KWT dalam mewujudkan Desa Agrowisata Sungai Langka.

\section{METODE PENELITIAN}

Penelitian ini menggunakan metode survei. Penentuan lokasi penelitian dilakukan secara sengaja (purposive) yaitu di Desa Sungai Langka, Kecamatan Gedong Tataan, Kabupaten Pesawaran, Provinsi Lampung. Populasi pada penelitian ini adalah anggota Kelompok Wanita Tani (KWT). Banyaknya unit sampel ditentukan menggunakan rumus Yamane (1967) dalam Rakhmat (2004), sehingga didapatkan sampel sebanyak 61 orang. Selanjutnya, jumlah masing-masing sampel tiap kelompok ditentukan menggunakan rumus Nazir (1988).

Penelitian ini menggunakan data primer dan data sekunder. Data primer diperoleh melalui proses wawancara, sedangkan data sekunder diperoleh dari studi kepustakaan, data umum potensi desa, serta instansi yang berkaitan dengan penelitian ini. Pengambilan data dilakukan pada bulan Januari 2018.
Variabel yang diduga berhubungan dengan peranan anggota KWT dalam mewujudkan Desa Agrowisata Sungai Langka adalah umur $\left(\mathrm{X}_{1}\right)$, tingkat pendidikan formal $\left(\mathrm{X}_{2}\right)$, motivasi $\left(\mathrm{X}_{3}\right)$, sifat kosmopolit $\left(\mathrm{X}_{4}\right)$ dan tingkat pengetahuan tentang desa agrowisata $\left(X_{5}\right)$. Pengukuran beberapa variabel di atas menggunakan teknik skoring (1-5). Data ordinal pada penelitian ini akan diubah menjadi data interval menggunakan metode MSI (Method Successive Interval).

Metode analisis menggunakan metode deskriptif dengan pendekatan kuantitatif. Analisis deskriptif digunakan untuk menjawab tujuan pertama, sedangkan untuk menjawab tujuan kedua menggunakan pendekatan kuantitif dengan metode analisis korelasi Rank Spearman (Siegel 1985) dengan bantuan SPSS versi 21. Kriteria pengambilan keputusan pada penelitian ini adalah sebagai berikut: 1) Jika $\mathrm{t}$ hitung $\geq \mathrm{t}$ tabel (pada $\alpha=$ 0,01) maka $\mathrm{H}_{1}$ diterima dan $\mathrm{H}_{0}$ ditolak, artinya terdapat hubungan yang nyata antara kedua variabel yang diuji. 2) Jika $t$ hitung $<t$ tabel (pada $\alpha=0,01)$ maka $\mathrm{H}_{1}$ ditolak dan $\mathrm{H}_{0}$ diterima, artinya tidak ada hubungan yang nyata antara kedua variabel yang diuji.

\section{HASIL DAN PEMBAHASAN}

\section{Karakteristik Umum Responden}

Berdasarkan hasil penelitian pekerjaan pokok responden antara lain ibu rumah tangga, petani, wiraswasta, peternak, jual sayur matang, pedagang sayuran dan produsen keripik. Mayoritas responden adalah ibu rumah tangga dengan persentase tertinggi $(73,77 \%)$. Jumlah anggota keluarga responden mayoritas sebanyak 2-4 orang dengan persentase tertinggi $(68,85 \%)$.

\section{Deskripsi Variabel X (Faktor-faktor yang Diduga Berhubungan dengan Peranan Anggota KWT)}

\section{$\operatorname{Umur}\left(\mathbf{X}_{1}\right)$}

Berdasarkan hasil penelitian, diperoleh umur responden berkisar antara $29-52$ tahun. Interval umur ditentukan berdasarkan umur hasil penelitian di lapangan, dan dibagi menjadi tiga klasifikasi yaitu, muda ( 29 - 37 tahun), setengah baya (38 44 tahun) dan tua (45 - 52 tahun). Umur responden dengan persentase tertinggi $(40,98 \%)$ berada pada klasifikasi umur muda dan persentase terendah $(19,67 \%)$ berada pada klasifikasi umur tua. Menurut Mantra (2004), terdapat tiga klasifikasi 
umur yaitu belum produktif $(0-14$ tahun $)$, produktif (15 - 64 tahun) dan tidak produktif (>65 tahun). Berdasarkan hasil perhitungan, didapat rata-rata umur responden adalah 38 tahun, yang berarti bahwa umur responden termasuk dalam klasifikasi umur produktif, sehingga responden memiliki potensi yang cukup besar untuk berperan pada kegiatan-kegiatan yang berkaitan dengan desa agrowisata.

\section{Tingkat Pendidikan Formal $\left(\mathbf{X}_{2}\right)$}

Berdasarkan hasil penelitian, pendidikan formal yang pernah ditempuh responden yaitu beragam mulai dari SD, SMP, SMA/SMK dan S1. Tingkat pendidikan formal responden dengan persentase tertinggi $(88,52 \%)$ berada pada pendidikan SMPSMA/SMK, sedangkan persentase terendah $(3,28 \%)$ berada pada pendidikan S1. Tingkat pendidikan formal merupakan potensi besar yang dapat mendukung responden untuk melaksanakan peranan dalam mewujudkan desa agrowisata ini.

\section{Tingkat Motivasi $\left(\mathbf{X}_{3}\right)$}

Berdasarkan hasil penelitian, tingkat motivasi responden dengan persentase tertinggi $(31,15 \%)$ berada pada klasifikasi sangat tinggi, sedangkan persentase terendah $(3,28 \%)$ berada pada klasifikasi sangat rendah, didapatkan nilai rata-rata tingkat motivasi sebesar 15,06 yang berarti bahwa tingkat motivasi responden termasuk dalam klasifikasi tinggi.

\section{Sifat Kosmopolit $\left(\mathbf{X}_{4}\right)$}

Berdasarkan hasil penelitian, sifat kosmopolit responden dengan persentase tertinggi $(27,87 \%)$ berada pada klasifikasi sedang, sedangkan persentase terendah $(13,11 \%)$ berada pada klasifikasi sangat tinggi, didapatkan rata-rata sifat kosmopolit sebesar 18,63 yang berarti sifat kosmopolit responden termasuk dalam klasifikasi sedang. Responden yang memiliki sifat kosmopolit rendah dan sangat rendah, dikarenakan masih banyak yang belum mengerti bagaimana penggunaan internet, bahkan terdapat responden yang tidak mempunyai handphone ios/android.

Penggunaan televisi dan radio hanya dimanfaatkan sebagai sarana hiburan saja, bukan untuk mencari informasi. Penggunaan majalah dan leaflet, mayoritas responden tidak pernah menggunakan kedua media massa tersebut. Responden yang memiliki sifat kosmopolit rendah dan sangat rendah dikarenakan mereka hanya beberapa kali saja mengikuti kegiatan ke luar desa yang berkaitan dengan desa agrowisata, bahkan ada yang tidak pernah ikut sama sekali. Untuk mengikuti kegiatan ke luar desa biasanya hanya diambil beberapa anggota saja sebagai perwakilan dan dilakukannya secara bergantian (rolling)

\section{Tingkat Pengetahuan $\left(\mathbf{X}_{5}\right)$}

Tingkat pengetahuan responden tentang desa agrowisata dengan persentase tertinggi $(24,59 \%)$ berada pada klasifikasi rendah, dan persentase terendah $(14,75 \%)$ berada pada klasifikasi sedang, didapatkan nilai rata-rata tingkat pengetahuan sebesar 7,08 yang berarti bahwa tingkat pengetahuan responden tentang desa agrowisata termasuk dalam klasifikasi sedang.

\section{Deskripsi Variabel Y (Peranan Anggota Kelompok Wanita Tani)}

Berdasarkan Tabel 1, peranan responden secara umum dengan persentase tertinggi $(29,51 \%)$ berada pada klasifikasi sedang, sedangkan persentase terendah $(11,48 \%)$ berada pada klasifikasi tinggi. Didapatkan nilai rata-ratanya yaitu 59,20 yang berarti bahwa peranan responden secara umum termasuk dalam klasifikasi sedang.

Tabel 1. Peranan anggota KWT dalam usaha mewujudkan desa agrowisata secara umum

\begin{tabular}{cccc}
\hline Interval & Klasifikasi & Jumlah (orang) & $\begin{array}{c}\text { Persentase } \\
(\%)\end{array}$ \\
\hline$(35,50-44,91)$ & Sangat rendah & 11 & 18,03 \\
$(44,92-54,33)$ & Rendah & 9 & 14,75 \\
$(54,34-63,74)$ & Sedang & 18 & 29,51 \\
$(63,75-73,15)$ & Tinggi & 16 & 26,23 \\
$(73,16-82,56)$ & Sangat tinggi & 7 & 11,48 \\
\hline Jumlah & & 61 & 100,00 \\
Rata-rata : 59,20 & & & \\
\hline
\end{tabular}

Tabel 2. Sebaran responden dalam pembuatan galeri petik sayur

\begin{tabular}{cccr}
\hline Interval & Klasifikasi & $\begin{array}{c}\text { Jumlah } \\
\text { (orang) }\end{array}$ & $\begin{array}{c}\text { Persentase } \\
(\%)\end{array}$ \\
\hline$(7,00-10,57)$ & Sangat rendah & 20 & 32,79 \\
$(10,58-14,13)$ & Rendah & 11 & 18,03 \\
$(14,14-17,70)$ & Sedang & 11 & 18,03 \\
$(17,71-21,27)$ & Tinggi & 7 & 11,48 \\
$(21,28-24,84)$ & Sangat tinggi & 12 & 19,67 \\
\hline Jumlah & & 61 & 100,00 \\
Rata-rata $: 14,42$ & & & \\
\hline
\end{tabular}


Pembahasan mengenai indikator pengukuran variabel Y akan diuraikan sebagai berikut.

\section{Pembuatan Galeri Petik Sayur}

Berdasarkan Tabel 2, peranan responden dalam pembuatan galeri petik sayur dengan persentase tertinggi $(32,79 \%)$ berada pada klasifikasi sangat rendah dan persentese terendah $(11,48 \%)$ berada pada klasifikasi tinggi. Nilai rata-rata Tabel 2 sebesar 14,42 yang berarti bahwa peranan responden dalam pembuatan galeri petik sayur termasuk dalam klasifikasi sedang. Berdasarkan hasil penelitian di lapangan, dusun yang telah melaksanakan galeri petik sayur antara lain dusun 2, 3, 6 dan 8, sedangkan dusun 1, 4 dan 5 belum melaksanakan. Kegiatan galeri petik sayur ini lebih dikhususkan kepada dusun 6 , sehingga peranan responden dusun 6 dalam kegiatan ini lebih tinggi dari pada responden dusun lainnya.

\section{Pembuatan Galeri Petik Buah}

Berdasarkan Tabel 3, peranan responden dalam pembuatan galeri petik buah dengan persentase tertinggi $(26,23 \%)$ berada pada klasifikasi sedang dan persentase terendah $(14,75 \%)$ berada pada klasifikasi rendah. Nilai rata-rata Tabel 3 sebesar 14,30 yang berarti peranan responden dalam pembuatan galeri petik buah ini termasuk dalam klasifikasi sedang. Berdasarkan hasil penelitian di lapangan, dusun yang telah melaksanakan kegiatan ini antara lain dusun 1, 3, 5, 6 dan 8, sedangkan yang belum melaksanakan yaitu dusun 2 dan 4 .

\section{Penanaman Pohon Nangka Mini}

Berdasarkan Tabel 4, peranan responden dalam penanaman pohon nangka mini dengan persentase tertinggi $(50,82 \%)$ berada pada klasifikasi sangat rendah, sedangkan persentase terendah $(6,56 \%)$ berada pada klasifikasi sangat tinggi. Nilai ratarata Tabel 4 sebesar 3,65 yang berarti peranan responden dalam kegiatan ini termasuk dalam klasifikasi rendah. Berdasarkan hasil penelitian di lapangan, rendahnya peranan responden dalam kegiatan ini karena mayoritas responden hanya melakukan pengolahan tanah dan penanaman saja, tidak melakukan kegiatan lainnya seperti yang terdapat pada indikator pengukuran, selain itu rendahnya peranan tersebut juga dikarenakan pada saat awal kegiatan ini dilaksanakan, terdapat beberapa warga khususnya responden yang tidak mendapatkan bibit pohon nangka mini tersebut.
Tabel 3. Sebaran responden dalam pembuatan galeri petik buah

\begin{tabular}{cccr}
\hline Interval & Klasifikasi & $\begin{array}{c}\text { Jumlah } \\
\text { (orang) }\end{array}$ & $\begin{array}{c}\text { Persentase } \\
(\%)\end{array}$ \\
\hline$(6,00-9,34)$ & Sangat rendah & 13 & 21,31 \\
$(9,35-12,69)$ & Rendah & 9 & 14,75 \\
$(12,70-16,03)$ & Sedang & 16 & 26,23 \\
$(16,04-19,37)$ & Tinggi & 12 & 19,67 \\
$(19,38-22,72)$ & Sangat tinggi & 11 & 18,03 \\
\hline Jumlah & & 61 & 100,00 \\
Rata-rata $: 14,30$ & & & \\
\hline
\end{tabular}

Tabel 4. Sebaran responden dalam penanaman pohon nangka mini

\begin{tabular}{cccr}
\hline Interval & Klasifikasi & $\begin{array}{c}\text { Jumlah } \\
\text { (orang) }\end{array}$ & $\begin{array}{c}\text { Persentase } \\
(\%)\end{array}$ \\
\hline$(2,00-3,01)$ & Sangat rendah & 31 & 50,82 \\
$(3,02-4,03)$ & Rendah & 5 & 8,20 \\
$(4,04-5,04)$ & Sedang & 5 & 8,20 \\
$(5,05-6,06)$ & Tinggi & 16 & 26,23 \\
$(6,07-7,07)$ & Sangat tinggi & 4 & 6,56 \\
\hline Jumlah & & 61 & 100,00 \\
Rata-rata $: 3,65$ & & & \\
\hline
\end{tabular}

\section{UKM Pengolahan Hasil Pertanian}

Berdasarkan Tabel 5, peranan responden dalam UKM pengolahan hasil pertanian dengan persentase tertinggi $(31,15 \%)$ berada pada klasifikasi tinggi, sedangkan persentase terendah $(11,48 \%)$ berada pada klasifikasi sangat rendah. Nilai rata-rata Tabel 5 sebesar 15,58 yang berarti peranan responden dalam UKM pengolahan hasil pertanian termasuk dalam klasifikasi sedang.

Berdasarkan hasil penelitian di lapangan, produkproduk yang dihasilkan oleh KWT Desa Sungai Langka antara lain; keripik tempe (Dusun 1), bubuk jahe (Dusun 2), keripik gadung, dodol pepaya, dodol labu kuning, dan dodol kulit pala (Dusun 3), keripik pisang, nangka, salak dan talas (Dusun 4), dodol labu siam dan bubuk biji salak (Dusun 5), bubuk coklat (Dusun 6), susu kambing cair/bubuk, keripik singkong dan manisan kates (Dusun 8).

Pada saat ini, dusun 4 menjadi sentra penghasil olahan hasil pertanian, khususnya untuk produk keripik pisang dan nangka. Penelitian ini sejalan dengan penelitian menurut Nurmayasari dan Ilyas (2014) yang menyatakan bahwa anggota KWT berperan aktif dalam kegiatan pengolahan hasil pertanian dan peternakan. 
Tabel 5. Sebaran responden dalam UKM pengolahan hasil pertanian

\begin{tabular}{cccc}
\hline Interval & Klasifikasi & $\begin{array}{c}\text { Jumlah } \\
\text { (orang) }\end{array}$ & $\begin{array}{c}\text { Persentase } \\
(\%)\end{array}$ \\
\hline$(6,00-9,60)$ & Sangat rendah & 7 & 11,48 \\
$(9,61-13,20)$ & Rendah & 9 & 14,75 \\
$(13,21-16,80)$ & Sedang & 17 & 27,87 \\
$(16,81-20,40)$ & Tinggi & 19 & 31,15 \\
$(20,41-23,99)$ & Sangat tinggi & 9 & 14,75 \\
\hline Jumlah & & 61 & 100,00 \\
Rata-rata : 15,85 & & & \\
\hline
\end{tabular}

Tabel 6. Sebaran responden berdasarkan pembuatan kerajinan tangan (cendera mata)

\begin{tabular}{cccr}
\hline Interval & Klasifikasi & $\begin{array}{c}\text { Jumlah } \\
\text { (orang) }\end{array}$ & $\begin{array}{c}\text { Persentase } \\
(\%)\end{array}$ \\
\hline$(6,00-8,93)$ & Sangat rendah & 30 & 49,18 \\
$(8,94-11,86)$ & Rendah & 2 & 3,28 \\
$(11,87-14,79)$ & Sedang & 11 & 18,03 \\
$(14,80-17,72)$ & Tinggi & 11 & 18,03 \\
$(17,73-20,66)$ & Sangat tinggi & 7 & 11,48 \\
\hline Jumlah & & 61 & 100,00 \\
Rata-rata : 10,98 & & & \\
\hline
\end{tabular}

\section{Pembuatan Kerajinan Tangan (Cendera Mata)}

Berdasarkan Tabel 6, persentase tertinggi $(49,18 \%)$ peranan responden dalam pembuatan kerajinan tangan dengan berada pada klasifikasi sangat rendah, sedangkan persentase terendah $(3,28 \%)$ berada pada klasifikasi rendah. Didapatkan nilai rata-ratanya sebesar 10,98 yang berarti peranan responden dalam kegiatan ini termasuk dalam klasifikasi rendah. Berdasarkan hasil penelitian di lapangan, rendahnya responden dalam kegiatan ini dikarenakan mayoritas kerajinan tangan yang dibuat adalah usaha individu bukan usaha kelompok, sehingga responden yang memang tidak memiliki usaha kerajinan tangan tersebut, ia tidak berperan. Usaha kerajinan tangan yang dihasilkan dari KWT Desa Sungai Langka antara lain; anyaman kipas bambu (Dusun 2), anyaman lidi (Dusun 8).

Usaha kerajinan tangan yang dihasilkan secara individu dari responden antara lain kerajinan tas tali kur, tapis lampung, anyaman koran, anyaman lidi, dan sulam motif tapis zaman now. Sulam motif tapis zaman now merupakan produk unggulan dari Desa Sungai Langka yang telah di hak patenkan menjadi hak milik Desa Sungai Langka dan dikerjakan secara individu maupun secara berkelompok.

\section{Pengujian Hipotesis}

Analisis hubungan antara variabel X (faktor-faktor yang berhubungan dengan peranan anggota KWT) dengan variabel Y (peranan anggota KWT dalam mewujudkan Desa Agrowisata Sungai Langka) menggunakan statistik non parametrik uji korelasi Rank Spearman dengan bantuan SPSS 21. Berdasarkan hasil analisis uji statistik, didapatkan variabel yang berhubungan nyata yaitu motivasi $\left(\mathrm{X}_{3}\right)$, sifat kosmopolit $\left(\mathrm{X}_{4}\right)$ dan tingkat pengetahuan $\left(\mathrm{X}_{5}\right)$, sedangkan yang tidak berhubungan nyata yaitu umur $\left(\mathrm{X}_{1}\right)$ dan tingkat pendidikan $\left(\mathrm{X}_{2}\right)$.

Berdasarkan hasil pengujian hipotesis hubungan umur dengan peranan anggota KWT didapatkan nilai koefisien korelasi Rank Spearman (rs) sebesar $0,27, \mathrm{t}$ hitung sebesar 2,20 dan $\mathrm{t}$ tabel 2,39 pada derajat signifikansi 0,01 . $\mathrm{t}$ hitung $<\mathrm{t}$ tabel, yang berarti bahwa tidak ada hubungan yang nyata antara umur responden dengan peranan anggota KWT dalam mewujudkan Desa Agrowisata Sungai Langka. Hasil penelitian ini tidak sejalan dengan penelitian Anindhita (2014), Ernitawati (2014), Gusra (2007) dan Widisasongko (2009).

Hubungan tingkat pendidikan dengan peranan anggota KWT didapatkan nilai koefisien korelasi Rank Spearman (rs) sebesar 0,20, t hitung sebesar 1,57 dan t tabel 2,39 pada derajat signifikansi 1,01. $\mathrm{t}$ hitung $<\mathrm{t}$ tabel, yang berarti bahwa tidak ada hubungan yang nyata antara tingkat pendidikan responden dengan peranan anggota KWT dalam mewujudkan Desa Agrowisata Sungai Langka. Tidak adanya hubungan yang nyata ini salah satunya dikarenakan dalam kurikulum di setiap jenjang pendidikan formal, responden tidak diberikan pelajaran tentang pelaksanaan program desa agrowisata tersebut, sehingga responden hanya diberikan informasi dan pengetahuan tentang program ini dari kegiatan penyuluhan atau pendidikan informal. Penelitian ini sejalan dengan penelitian Susanti dan Tantoro (2015) yang menyatakan bahwa tingkat pendidikan berhubungan nyata dengan peranan istri (anggota KWT).

Hubungan motivasi dengan peranan anggota KWT didapatkan nilai koefisien korelasi Rank Spearman (rs) sebesar 0,53, thitung sebesar 4,88 dan t tabel 2,39 pada derajat signifikansi 0,01. $\mathrm{t}$ hitung $>\mathrm{t}$ tabel, yang berarti bahwa ada hubungan yang nyata antara motivasi responden dengan peranan anggota KWT dalam mewujudkan Desa Agrowisata Sungai Langka. Penelitian ini sejalan dengan penelitian 
Anindhita (2014), Endang, Tenaya, dan Asiti (2014), Widisasongko (2009) dan Rahmawati (2012).

Hubungan sifat kosmopolit dengan peranan anggota KWT didapatkan nilai koefisien korelasi Rank Spearman (rs) sebesar 0,61, thitung sebesar 6,03 dan $\mathrm{t}$ tabel 2,39 pada derajat signifikansi 0,01. thitung $>\mathrm{t}$ tabel, yang berarti bahwa ada hubungan yang nyata antara sifat kosmopolit responden dengan peranan anggota KWT dalam mewujudkan Desa Agrowisata Sungai Langka. Penelitian ini sejalan dengan penelitian Gusra (2007).

Hubungan tingkat pengetahuan dengan peranan anggota KWT didapatkan nilai koefisien korelasi Rank Spearman (rs) sebesar 0,71, t hitung sebesar 7,74 dan t tabel 2,39 pada derajat signifikansi 0,01. $\mathrm{t}$ hitung $>\mathrm{t}$ tabel, yang berarti bahwa ada hubungan yang nyata antara tingkat pengetahuan responden dengan peranan anggota KWT dalam mewujudkan Desa Agrowisata Sungai Langka. Penelitian ini sejalan dengan penelitian Ernitawati (2014), Rahmawati (2012) dan Widisasongko (2009).

\section{KESIMPULAN}

Berdasarkan hasil penelitian dapat disimpulkan bahwa peranan anggota KWT dalam penanaman pohon nangka mini dan pembuatan kerajinan tangan (cendera mata) termasuk dalam klasifikasi rendah, peranan anggota KWT dalam pembuatan galeri petik sayur, petik buah dan dalam UKM Pengolahan hasil pertanian termasuk dalam klasifikasi sedang, sedangkan peranan anggota KWT secara umum dalam mewujudkan Desa Agrowisata Sungai Langka termasuk dalam klasifikasi sedang. Faktor-faktor yang berhubungan nyata dengan peranan anggota KWT yaitu tingkat motivasi, sifat kosmopolit dan tingkat pengetahuan tentang program, sedangkan yang tidak berhubungan nyata yaitu umur dan tingkat pendidikan formal.

\section{DAFTAR PUSTAKA}

Anindita F. 2014. Pengaruh Peranan Kelompok Wanita Tani Terhadap Pelaksanaan Program P2KP di Kabupaten Temanggung. Skripsi. Universitas Gadjah Mada. Yogyakarta.

Badan Litbang Pertanian. 2015. Peran Kelompok Wanita Tani Dalam Pemanfaatan Pekarangan di Kota Palopo. Sulawesi Selatan.

Gusra R. 2007. Peranan Anggota Kelompok Tani Dalam Program Bantuan Langsung Masyarakat Bergulir (BLMB) pada kegiatan
Pengembangan Pusat Pertumbuhan (P3) padi di Pekon Pajaresuk Kecamatan Pringsewu Tanggamus. Skripsi. Universitas Lampung. Bandar Lampung.

Endang PR, Tenaya MN dan Astiti NWS. 2014. Peran Wanita tani dalam penerapan teknologi pengelolaan tanaman terpadu (PTT) pada usaha tani jagung di Kecamatan Pringgabaya Kabupaten Lombok Timur. Jurnal Manajemen Agribisnis, 2 (1) :76-83. http:// erepo.unud.ac.id/3620/. [28 Juni 2018].

Ernitawati S. 2014. Peranan Wanita Tani Dalam Penerapan Teknologi Budidaya Sayuran Di Lahan Pasir Pantai kecamatan Sanden Kabupaten Bantul. Skripsi. Universitas Gadjah Mada. Yogyakarta.

Hubeis AVS. 2010. Pemberdayaan Perempuan Dari Masa ke Masa. IPB Press. Bogor.

Korten D dan C Syahrir. 1988. Pembangunan Berdimensi Rakyat. Yayasan Obor Indonesia. Jakarta.

Laboratorium Desa. 2017. Jumlah Kebun Rakyat Desa Sungai Langka. Fakultas Pertanian, Universitas Lampung. Bandar Lampung.

Mantra IB. 2004. Demografi Umum. Pustaka Pelajar. Yogyakarta.

Maruti. 2009. Agrowisata : Ekonomi Kreatif. Mandar Maju. Jakarta.

Nazir. 1988. Metode Penelitian. Ghalia Indonesia. Jakarta.

Nurmayasari D dan Ilyas. 2014. Peran anggota kelompok wanita tani (KWT) "Laras Asri" pada peningkatan kesejahteraan keluarga. Journal of Non Formal Education and Community Empowerment, 3 (2) : 16-21. https://journal.unnes.ac.id/sju/index.php/jnfc/a rticle/view/3728. [28 Juni 2018].

Rahmawati E. 2012. Peranan Anggota Kelompok Peternak Sapi Brahman Cross dalam Program Bantuan Langsung Masyarakat (BLM) di Desa Tanjung Tirto Kecamatan Way Bungur Kabupaten Lampung Timur. Skripsi. Universitas Lampung. Bandar Lampung.

Rakhmat J. 2004. Metode Penelitian Komunikasi. Rosdakarya. Bandung.

Siegel S. 1985. Statistika Nonparametrik, Suatu Tafsiran dari Nonparametrik Statistics for Behavioral Sciences, oleh M. Sudrajat SW. PT. Armico. Bandung.

Susanti R dan Tantoro S. 2015. Peran istri dalam perekonomian keluarga di Desa Parit Baru Kecamatan Tambang Kabupaten Kampar. Jurnal Online Mahasiswa FISIP, 2 (1):9-22. http://jom.unri.ac.id/index.php/JOMFSIP/artic le/view/5021. [28 Juni 2018]. 


\section{JIIA, VOLUME 6 No. 4, NOVEMBER 2018}

Widisasongko P. 2009. Faktor-faktor yang Berhubungan dengan Peranan Anggota dan Tingkat Keberhasilan Koperasi (studi kasus pada Koperasi Wanita "Cempaka" Kampung
Astromulyo Kecamatan Punggur Kabupaten Lampung Tengah. Skripsi. Universitas Lampung. Bandar Lampung. 